\title{
Electrochemical and Atomic Force Microscopy Investigations of New Materials from N-Trifluoromethanesulfonyl-1-azahexa-1,3,5-trienes Derivatives
}

\author{
Margarita Rivera $^{*, a}$, Cecilio Alvarez-Toledano ${ }^{b}$, Abel Moreno ${ }^{b}$, José D. Sepúlveda-Sánchez, $^{c}$, \\ Tomás Hernández-Pérez a and María E. Sánchez-Vergara ${ }^{e}$
}

${ }^{a}$ Instituto de Física and ${ }^{b}$ Instituto de Química, Universidad Nacional Autónoma de México, Ciudad Universitaria, 04510 México, D.F., México

${ }^{c}$ Laboratorio de Microscopía Electrónica, Universidad Autónoma Metropolitana-Iztapalapa, 09340 México, D.F., México

${ }^{d}$ Departamento de Ciencias Básicas, Universidad Autónoma Metropolitana-Azcapotzalco, 02200 México, D.F., México

e Departamento de Ingeniería Mecánica, I.T.E.S.M., Campus Ciudad de México, 14380 México, D.F., México

\begin{abstract}
Filmes finos foram crescidos sobre a superfície de elétrodos de grafito pirolizado altamente orientado a partir de precursores p-doadores utilizando a técnica cíclica de voltametria cíclica e eletroquímica-microscopia de força atômica. Os resultados indicam que é possível a formação de novos compostos chamados materiais moleculares, estes são formados pelo acoplamento de espécies $\mathrm{N}$-trifluormetanosulfonil-1-aza-hexa-1,3,5-trieno eletro-oxidadas e o anion $\left[\mathrm{Cr}\left(\mathrm{C}_{2} \mathrm{O}_{4}\right)_{3}\right]^{3-}$. Diferentes técnicas foram empregadas para caracterizar a morfologia e composição dos filmes formados. Os resultados indicam que os materiais novos exibiram uma resposta eletroquímica particular e uma textura diferente dependendo da composição química dos materiais de partida.
\end{abstract}

Thin films have been created on the surface of highly oriented pyrolytic graphite electrodes from chemically synthesized $\pi$-donor species by using the cyclic voltammetry technique and in situ electrochemistry-atomic force microscopy. Results indicate that it is possible to form new compounds called molecular materials from the coupling of electro-oxidized N-trifluoromethanesulfonyl-1-azahexa-1,3,5-triene species and a $\left[\mathrm{Cr}\left(\mathrm{C}_{2} \mathrm{O}_{4}\right)_{3}\right]^{3-}$ anion. Different techniques such as AFM, SEM and EDS were employed to characterize the films morphology and composition. Results indicate that the new materials exhibited a particular electrochemical response and a different film texture depending on the chemical composition of the starting compounds.

Keywords: thin films, electrodeposition, in situ AFM

\section{Introduction}

Over the last few years, there have been an increasing number of reports regarding the formation of molecular materials (MMs) with electronic or opto electronic properties based on organic and organometallic derivatives. ${ }^{1,2}$ For example, it has been reported the formation of supramolecular building blocks with tailored pore structures by Plaud et al. to generate predictable and robust structures for specific applications. ${ }^{3}$ Moreover, recent

\footnotetext{
* e-mail: mrivera@servidor.unam.mx
}

research work has been oriented to the formation and characterization of molecular-material thin films. ${ }^{4}$ For instance, the use of the chemical vapor deposition to grow thin films of molecular conductors such as (TTF)(TCNQ) $(\mathrm{TTF}=$ tetrathiafulvalene, $\mathrm{TCNQ}=$ tetracyanoquinodimethane) has been reported. ${ }^{5-8}$

It has been observed, that a regular stacking of molecules such as those found in MMs allows the formation of semiconducting, conducting or superconducting thin films. These thin films exhibit in general preferential directions for electrical conductivity. The electrical conductivity of MMs is associated with an extensive delocalization of electrons that depends on their 
planarity and the orbital overlap extension between their molecular units. N-Trifluoromethanesulfonyl-1-azahexa1,3,5-trienes (TFSAT) compounds, which are highly functionalized pentametines, have been previously studied due to its interesting physical and chemical properties. ${ }^{9}$ These compounds are especially interesting from a structural point of view for some reasons; in a neutral form, they show an extensive electronic delocalization, which give them a very particular chemical behavior. Furthermore, these pentametines can work as monodentate ligands, bidentate ligands, and even interact with metals through $\pi$ electrons. ${ }^{9}$ Due to its planar structure, it is evident that the TFSAT molecules are excellent candidates to form new MMs in a similar way as the TTF complexes do. ${ }^{6}$ Therefore, the aim of this work is to study the voltammetric formation of new materials by the coupling of TFSTA molecules and a magnetic anion. The magnetic $\left[\mathrm{Cr}\left(\mathrm{C}_{2} \mathrm{O}_{4}\right)_{3}\right]^{3-}$ specie was used since similar transition metal complexes have been employed in the formation of other MMs. ${ }^{10,11}$ In this work, the in situ film formation of novel compounds on the surface of high oriented pyrolytic graphite (HOPG) electrodes was performed by using a combined technique based on electrochemistry and atomic force microscopy (EC-AFM). The films morphology and composition was studied with atomic force microscopy, scanning electron microscopy and energy dispersive spectroscopy.

\section{Experimental}

Compounds (1) 1-trifluoromethanesulfonyl-6-phenilamine-1-azahexa-1,3,5-triene, (2) 1-trifluoromethanesulfonyl-3-cloro-6-phenilamine-1-azahexa-1,3,5-triene, (3) 1-trifluoromethanesulfonyl-3-[4'-(1'-trifluoromethanesulfonyl)-1',4' -dihydropyridinyl]-6-alylamine)-1azahexa-1,3,5-triene and (4) 1-trifluoromethanesulfonyl3-[2'(-(S)-(1'-methyl) pyrrolidine)]-6-methylphenilamine1-azahexa-1,3,5-triene were employed as donor species (DS) (see Figure 1). These $\pi$-donor chemical species were synthesized according to Moya. ${ }^{12}$ On the other hand, the $\left[\mathrm{Cr}\left(\mathrm{C}_{2} \mathrm{O}_{4}\right)_{3}\right]^{3-}$ anion was used since it has proved to be a good transition metal complex in the formation of different MMs. ${ }^{9,10}$ All chemicals were reagent-grade products from commercial suppliers and they were used without further purification.

The thin films were obtained from ethanol/water (10\%, v/v) dissolutions at $25^{\circ} \mathrm{C}$. The $\mathrm{K}_{3}\left[\mathrm{Cr}\left(\mathrm{C}_{2} \mathrm{O}_{4}\right)_{3}\right] \cdot 3 \mathrm{H}_{2} 0$ salt was used as both, $\pi$-acceptor specie (AS) and support electrolyte. Then, the dissolution with the donor $\left(1 \times 10^{-4}\right.$ mol L $\left.{ }^{-1}\right)$ and the acceptor $\left(1 \times 10^{-3} \mathrm{~mol} \mathrm{~L}^{-1}\right)$ species was introduced in the electrochemical fluid cell (ca. $20 \mu \mathrm{L})$ of
(1)<smiles>O=S(=O)(N=CC=CC=CNc1ccccc1)OC(F)(F)F</smiles>

(2)<smiles>O=S(=O)(N=CC(Cl)=CC=CNc1ccccc1)OF</smiles>

(3)<smiles>C=CCN/C=C/C=C(/C=C/S(O)(O)(O)(F)F)C1C=CN(S(C)(F)(F)(F)F)C=C1</smiles>

(4)<smiles>CN(/C=C/C=C(/C=N[Sb](O)(O)C(F)(F)F)C1CCCN1)c1ccccc1</smiles>

Figure 1. Chemical structure of pentametines.

a NanoScope IIIa Atomic Force Microscope (AFM) from Digital Instruments, Co. Here, the cyclic voltammetry (CV) and the surface morphology of the electrodeposited materials were investigated by in situ EC-AFM.

In this case, a fresh cleaved HOPG surface was used as a working electrode, $\mathrm{Pt}$ wire as a counter electrode and $\mathrm{Ag}$ wire as a pseudo-reference electrode. The EC-AFM experiments were run using cyclic voltammetry between the cathodic $(-1.0 \mathrm{~V})$ and anodic $(+1.0 \mathrm{~V})$ switching potentials. The scan rate was $75 \mathrm{mV} \mathrm{s}^{-1}$. The morphological characterization by AFM of the new electrodeposited materials was performed in situ in the contact mode using low scanning forces $\left(0.3 \mathrm{~N} \mathrm{~m}^{-2}\right)$ at the open circuit mode. Finally, elemental analysis of the electrodeposited films was performed with a Scanning Electron Microscope JSM 5900 LV coupled to an X-Ray Energy Dispersive Spectrometer working at $20 \mathrm{KeV}$.

\section{Results and Discussion}

In order to investigate the redox behavior of the starting compounds to discard an independent reaction of the solutions, a cyclic voltammetry study on each of them was 
performed. The chromium complex (Figure 2a) as well as donor species 1, 2 and $\mathbf{4}$ did not show any potential peaks in the switching interval. Moreover, surface characterization of the working electrodes by AFM and SEM did not show the presence of any electrodeposited material in these cases. On the other hand, Figure $2 b$ shows the cyclic voltammetry response of donor specie $\mathbf{3}$ alone. Here, we can see in the first positive going scan an oxidation peak at $+420 \mathrm{mV}$ and a very small reduction peak at $+50 \mathrm{mV} v s$. Ag. After the first cycle, the voltammetric profile was considerably different exhibiting an important decrease in current density.

In the presence of the $\left[\mathrm{Cr}\left(\mathrm{C}_{2} \mathrm{O}_{4}\right)_{3}\right]^{3-}$ anion, the voltammetric response of various DS changed considerably since the anodic oxidation of aromatic amines is quite complex, leading to a variety of products depending on their structure and electrolysis conditions. ${ }^{13}$

For instance, the voltammetric behavior of compound DS1 and the $\left[\mathrm{Cr}\left(\mathrm{C}_{2} \mathrm{O}_{4}\right)_{3}\right]^{3-}$ anion showed anodic and cathodic peak currents at $+571 \mathrm{mV}$ and $+233 \mathrm{mV}$. On the other hand, DS2 and $\left[\mathrm{Cr}\left(\mathrm{C}_{2} \mathrm{O}_{4}\right)_{3}\right]^{3-}$ showed a voltammetric response with only one anodic peak at $+900 \mathrm{mV}$. Figure $2 \mathrm{c}$
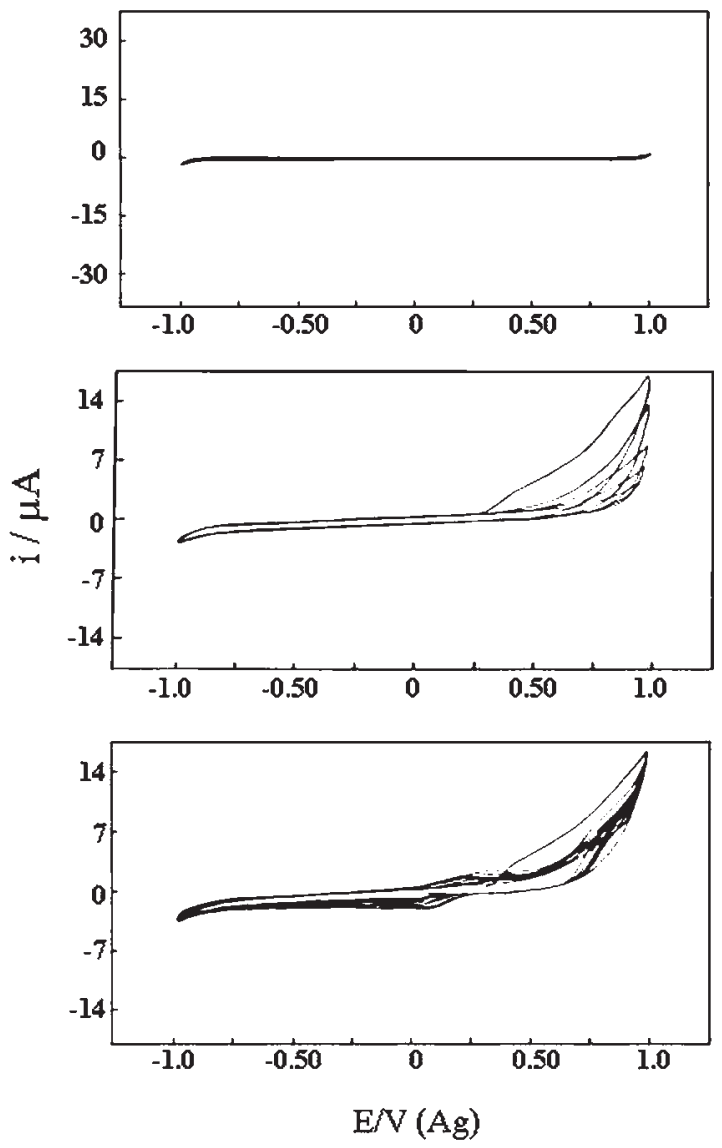

Figure 2. Cyclic voltammogram for the ethanol-water dissolution containing a) the $\mathrm{K}_{3}\left[\mathrm{Cr}\left(\mathrm{C}_{2} \mathrm{O}_{4}\right)_{3}\right] \cdot 3 \mathrm{H}_{2} 0$ anion alone after 5 PSC, b) DS3 alone after 5 PSC and c) DS3 and $\mathrm{K}_{3}\left[\mathrm{Cr}\left(\mathrm{C}_{2} \mathrm{O}_{4}\right)_{3}\right] \cdot 3 \mathrm{H}_{2} 0$ species combined after 10 PSC. The potential sweep rate was $75 \mathrm{mV} \mathrm{s}^{-1}$. shows the voltammogram by using DS3 and the $\left[\mathrm{Cr}\left(\mathrm{C}_{2} \mathrm{O}_{4}\right)_{3}\right]^{3-}$ anion after 10 potential scan cycles (PSC). From this plot, in the first cycle an anodic potential at $+420 \mathrm{mV}$ vs. Ag, which corresponds to the electrochemical oxidation of DS3 alone, is observed. On the second cycle, this oxidation peak disappeared but two other potentials at $+63 \mathrm{mV}$ (cathodic) and $+213 \mathrm{mV}$ (anodic) appeared as the number of PSC increased. This voltammetric response suggests that the first oxidation potential corresponds to the redox response of compound DS3 alone while the other two potentials of the next cycles correspond to the redox behavior of the combined species DS3 and $\left[\mathrm{Cr}\left(\mathrm{C}_{2} \mathrm{O}_{4}\right)_{3}\right]^{3-}$. Furthermore, as the number of cycles increased, the anodic and cathodic peak currents increased too. This behavior suggested that some material was electrodeposited on the HOPG surface by the cyclic voltammetry process in a similar way as an organic or inorganic conducting polymer does. ${ }^{13,14}$ Finally, the voltammetric response of compound DS4 and the $\left[\mathrm{Cr}\left(\mathrm{C}_{2} \mathrm{O}_{4}\right)_{3}\right]^{3-}$ anion does not show any potential peaks within the switching interval. In both extremes (at the limit potentials), a current increase is observed which can be associated with the increased deposition of material on the substrate.

Figure 3 shows the AFM images of the electrode surface after: a) 0 (bare $\mathrm{HOPG}$ surface) and b) 30 potential scan cycles (PSC) by using DS1 and the $\left[\mathrm{Cr}\left(\mathrm{C}_{2} \mathrm{O}_{4}\right)_{3}\right]^{3-}$ anion.

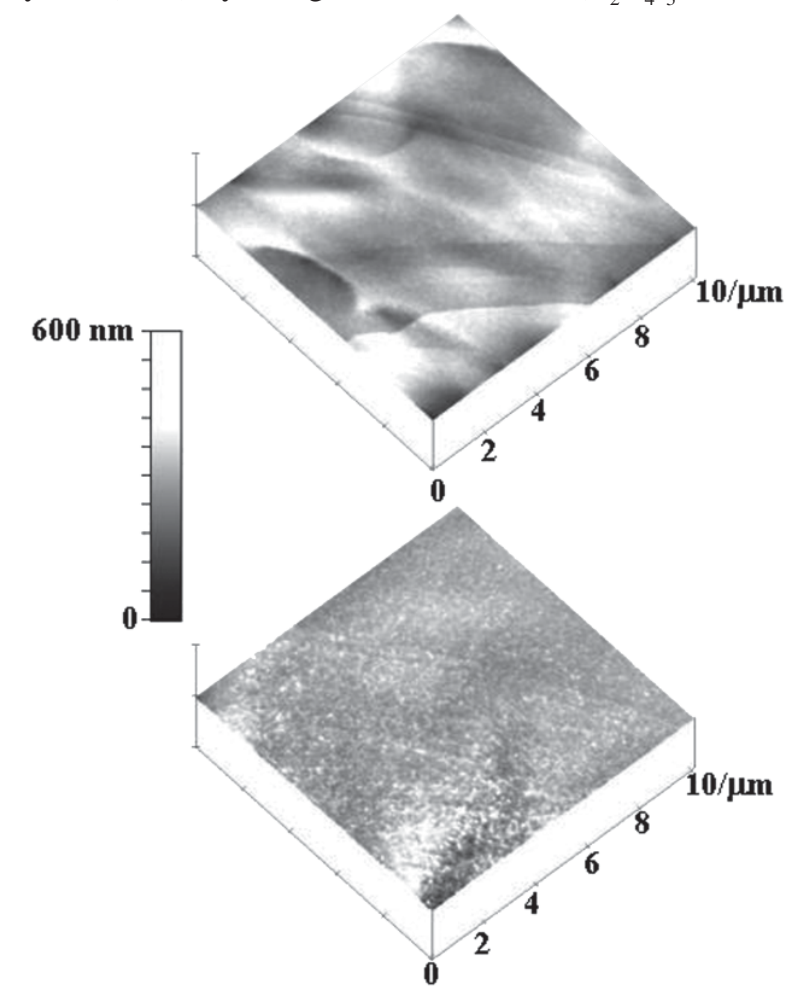

Figure 3. In situ AFM images of the electrode surface after: a) none (bare HOPG) and b) 30 PSC for the electrodeposited material from the combined species DS1 and $\mathrm{K}_{3}\left[\mathrm{Cr}\left(\mathrm{C}_{2} \mathrm{O}_{4}\right)_{3}\right] \cdot 3 \mathrm{H}_{2} 0$. Images sizes are $10 \times 10 \mu \mathrm{m}$. 
The electrodeposited material in this case is almost uniformly distributed on the electrode surface and the final film texture is thin and grainy. From the vertical scale bar, it is clear that the size of the grains is very small. A root mean square (RMS) roughness analysis of the surface, which is a quantitative measurement of the film texture, shows that after 40 PSC the film did not change and its final RMS value was $21 \mathrm{~nm}$. The surface morphology of the materials on the electrode surface as seen by AFM by using the $\left[\mathrm{Cr}\left(\mathrm{C}_{2} \mathrm{O}_{4}\right)_{3}\right]^{3-}$ anion and the DS2 and DS4 compounds was very similar. For instance, Figure 4 shows the AFM images of the electrode after: a) 5 and b) 35 PSC from DS4 and $\left[\mathrm{Cr}\left(\mathrm{C}_{2} \mathrm{O}_{4}\right)_{3}\right]^{3-}$. In these images, it is observed a regular distributed granular material with a RMS value of $7.1 \mathrm{~nm}$ after $35 \mathrm{PSC}$, which suggests a thin film formation. Finally, Figure 5 shows the AFM images corresponding to the DS3 compound. Figure 5a shows the electrode surface after 15 PSC using DS3 only. The surface is barely modified although two small spots appeared on the electrode surface. In the presence of the $\left[\mathrm{Cr}\left(\mathrm{C}_{2} \mathrm{O}_{4}\right)_{3}\right]^{3-}$ anion, the film exhibits an important amount of electrodeposited material after 15 PSC as seen in Figure $5 \mathrm{~b}$. Here, the growth of randomly distributed nodules is observed. For instance, a section analysis of the surface (not shown here) determined features of different heights (up to two microns) irregular distributed on the electrode

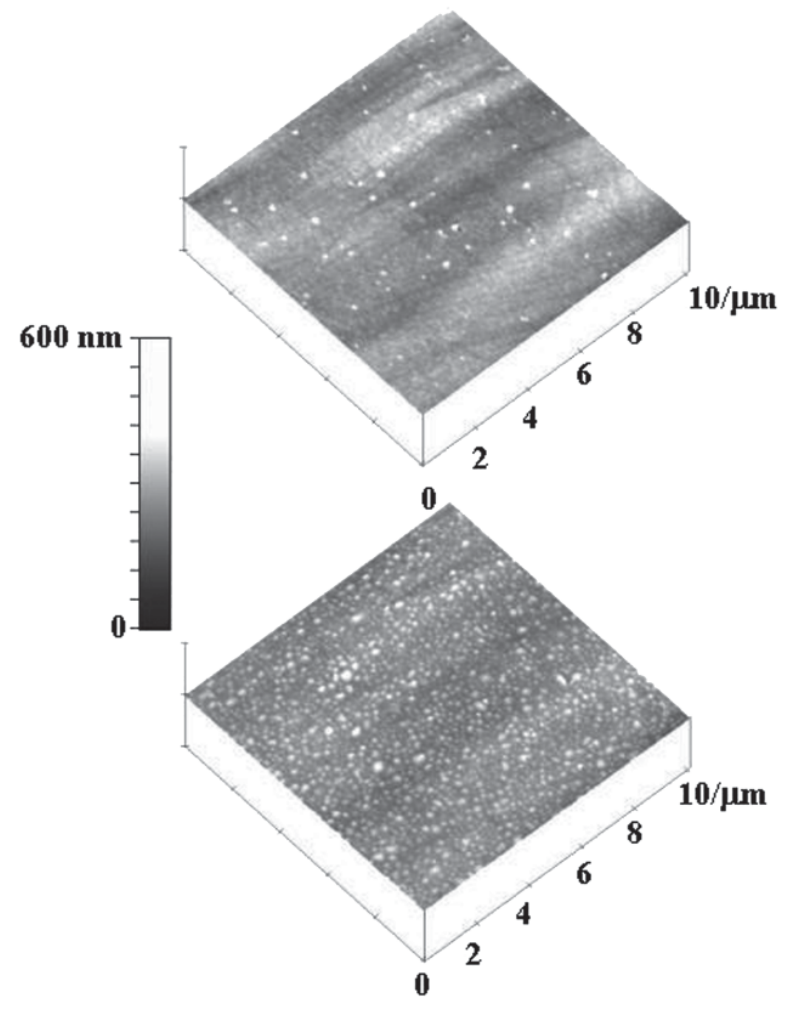

Figure 4. In situ AFM images of the HOPG electrode surface after: a) 5 and b) 35 PSC for the electrodeposited material from the combined species DS4 and $\mathrm{K}_{3}\left[\mathrm{Cr}\left(\mathrm{C}_{2} \mathrm{O}_{4}\right)_{3}\right] \cdot 3 \mathrm{H}_{2} 0$. Images sizes are $10 \times 10 \mu \mathrm{m}$. surface. In this case, the surface coverage was not uniform and the RMS roughness value after 15 PSC was $79 \mathrm{~nm}$.

After the electrodeposition process, SEM and EDS analysis were performed to investigate the surface coverage and to identify the composition of the newly formed films. All SEM images showed homogeneous textures irregular distributed with a partial surface coverage of the electrode surface. For instance, EDS analysis of the spots on the electrodeposited material from DS3 only, showed the elements contained in the complex alone (fluorine, chlorine and sulphur) plus the carbon contained in the working electrode. Figure 6 shows the SEM of the electrode surface after the DS3 and the $\left[\mathrm{Cr}\left(\mathrm{C}_{2} \mathrm{O}_{4}\right)_{3}\right]^{3-}$ anion electrodeposition. Figure 7 shows the EDS analysis of the materials obtained from the $\left[\mathrm{Cr}\left(\mathrm{C}_{2} \mathrm{O}_{4}\right)_{3}\right]^{3-}$ anion and a) DS1 and b) DS4. Table 1 shows the chemical analysis for all four synthesized materials where the presence of reference elements for both, donor (fluorine, chlorine and sulphur) and acceptor species (chromium and potassium), is observed. The presence of $\mathrm{Cr}$ in every one of the newly formed compounds suggests that they are formed by the reaction of the TFSAT and the $\left[\mathrm{Cr}\left(\mathrm{C}_{2} \mathrm{O}_{4}\right)_{3}\right]^{3-}$ species since the $\left[\mathrm{Cr}\left(\mathrm{C}_{2} \mathrm{O}_{4}\right)_{3}\right]^{3-}$ anion alone did not show a redox reaction by itself. The presence of potassium in the electrodeposits suggests that in the oxidized state, the anion gets into the new solid phase and remains inside the film. Since the MMs show a negative

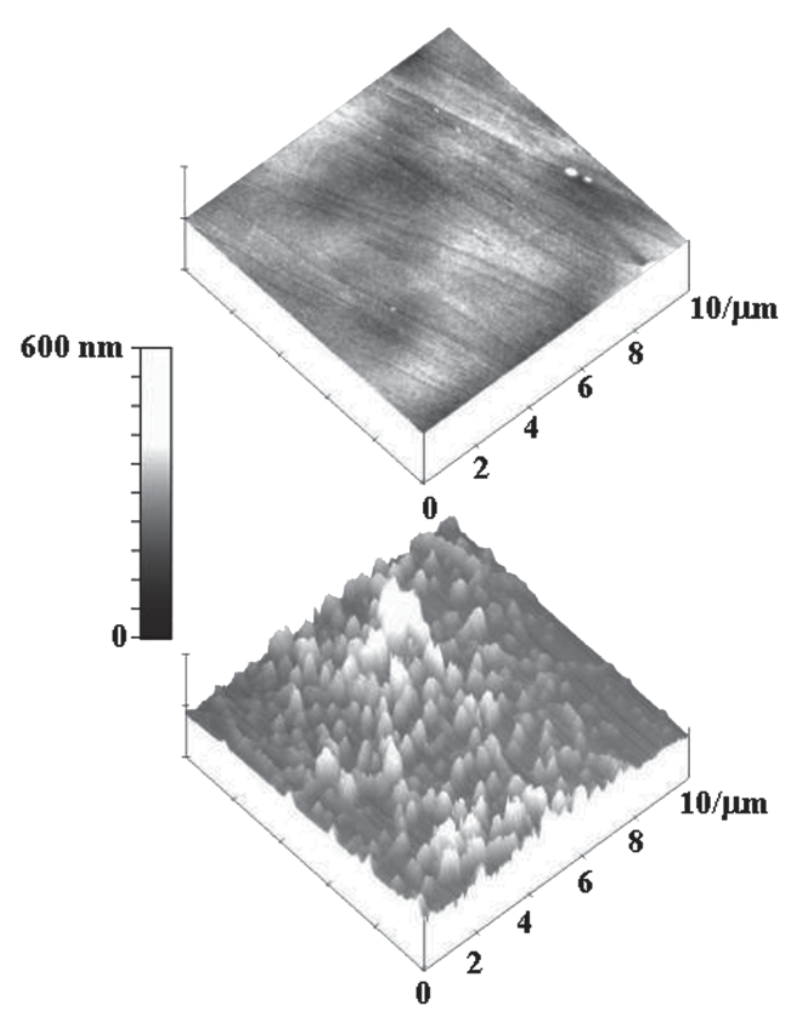

Figure 5. In situ AFM images of the HOPG electrode surface for: a) DS3 alone after 15 PSC and $b$ ) the combined species DS3 and $\mathrm{K}_{3}\left[\mathrm{Cr}\left(\mathrm{C}_{2} \mathrm{O}_{4}\right)_{3}\right] \cdot 3 \mathrm{H}_{2} 0$ after 15 PSC. Images sizes are $10 \times 10 \mu \mathrm{m}$. 
charge due to the presence of the anion, $\mathrm{K}^{+}$cations get into the MMs films and remain inside in order to neutralize the negative charge. This behavior is similar to that

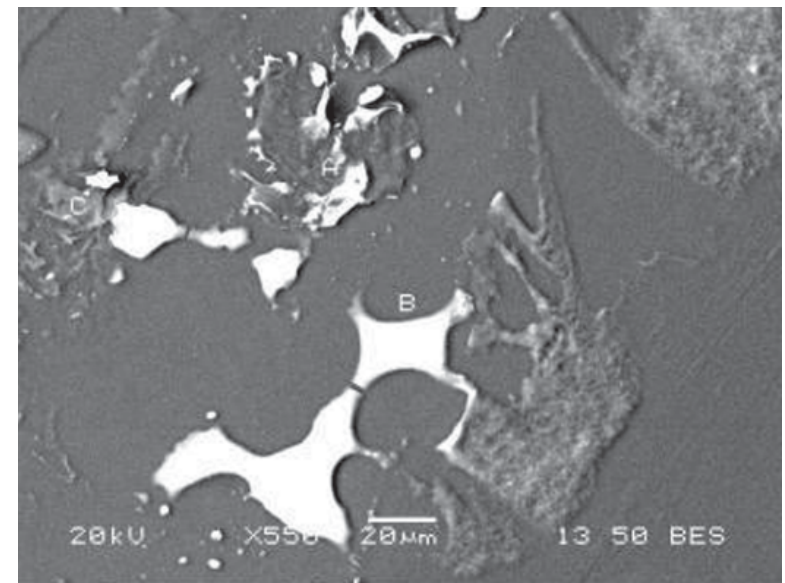

Figure 6. SEM image of the electrodeposited material from the combined species DS3 and $\mathrm{K}_{3}\left[\mathrm{Cr}\left(\mathrm{C}_{2} \mathrm{O}_{4}\right)_{3}\right] \cdot 3 \mathrm{H}_{2} 0$ after 30 PSC.

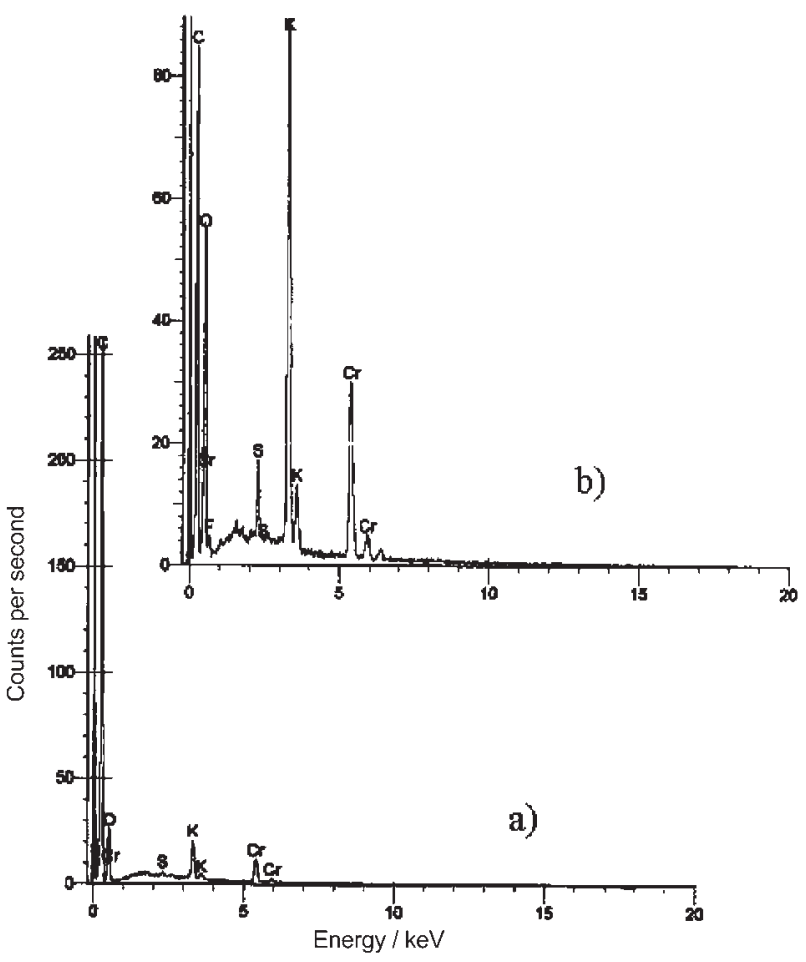

Figure 7. EDS analysis of the electrodeposited material from the combined species $\mathrm{K}_{3}\left[\mathrm{Cr}\left(\mathrm{C}_{2} \mathrm{O}_{4}\right)_{3}\right] \cdot 3 \mathrm{H}_{2} 0$ with a) DS1 and b) DS4. The presence of reference elements is observed.

Table 1. EDS analysis of the electrodeposited films on the HOPG electrode

\begin{tabular}{llllllll}
\hline $\mathrm{MM}$ & $\% \mathrm{C}$ & $\% \mathrm{O}$ & $\% \mathrm{~S}$ & $\% \mathrm{~K}$ & $\% \mathrm{Cr}$ & $\% \mathrm{Cl}$ & $\% \mathrm{~F}$ \\
\hline 1 & 74.39 & 21.80 & 0.13 & 1.67 & 2.01 & - & - \\
2 & 77.88 & 18.70 & 0.15 & 1.76 & 0.71 & 0.10 & 0.70 \\
3 & 76.42 & 17.38 & 0.23 & 3.99 & 1.40 & - & 0.58 \\
4 & 42.05 & 38.92 & 0.97 & 9.29 & 6.18 & - & 2.59 \\
\hline
\end{tabular}

observed for conductive polymers formed in the presence of anions of large size. ${ }^{15}$

It is well known that aromatic amines are usually very easy to oxidize. ${ }^{16}$ Moreover, the anodic oxidation of aromatic amines is quite complex, leading to a variety of products depending on their structure and their electrolysis conditions. ${ }^{16}$ Under these circumstances, the reaction mechanism for the formation of the new material from DS1, involved an electrocyclic aperture preceded by an aniline nucleophilic attack on the pyridinium salt. ${ }^{17}$ The molecule existed in the betainic form ${ }^{17}$ where a negative charge was distributed on the trifluoromethansulfonylamide group and a positive charge was distributed on the amine group. The synthesis of compound $\mathbf{2}$ was formed from the attack of the aniline to the trifluoromethansulfonate N-trifluoromethansulfonyl-3-cloropyridone salt. Apparently, a steric or electronic effect in this compound exists that generates a magnetic anisotropy, due to the orientation of $\mathrm{CF}_{3}$ in opposite sides of the molecule. ${ }^{7}$ In this case, the chlorine compound showed a null steric and electronic effect in contrast to its non-chlorined analog.

On the other hand, the nucleophilic aperture of alylamine on the pyridone salt ${ }^{7}$ originated the material from DS3. Apparently, this compound is the one that more easily produces a new material with the $\mathrm{K}_{3}\left[\mathrm{Cr}\left(\mathrm{C}_{2} \mathrm{O}_{4}\right)_{3}\right] \cdot 3 \mathrm{H}_{2} \mathrm{O}$ salt due to the limited stability of the starting compound (DS3). This result is supported by AFM images of the electrode surface where large amounts of electrodeposited material are observed. Finally, the aperture of the nicotine derivative salt synthesized the material from DS4 as it incorporated an electrodonor substitute (N-metilfenylamine) in the basic framework of the 1-azahexatriene system. ${ }^{7}$ As a result, a very stable compound with low potentiality to interact with the $\mathrm{K}_{3}\left[\mathrm{Cr}\left(\mathrm{C}_{2} \mathrm{O}_{4}\right)_{3}\right] \cdot 3 \mathrm{H}_{2} 0$ salt was obtained. This again is supported by AFM since image $4 \mathrm{~b}$ shows a fine grain thin film covering the electrode surface, which suggests the electrodeposition of very small amounts of new material.

From the voltammetry results, it can be observed that new materials created with donor species $\mathbf{1}$ and $\mathbf{3}$ showed anodic/cathodic peak differences $(\Delta \mathrm{E})$ in accordance with the Saito and Ferraris criterion for the formation of products called Molecular Materials from the reaction of compounds with similar characteristics. ${ }^{18}$ It is interesting to mention that the electrochemical response of the materials obtained from DS2 and DS4 did not show cathodic and anodic peaks (only an anodic peak for DS2) and therefore, they do not obey this criterion but the presence of a new amorphous material on the electrode surface establishes a surface modification by electrodeposition. Therefore, it can be inferred that their oxidation is irreversible or the 
electrodeposited films are non-electroactive. In the same sense, the absence of voltammetric peaks may also suggests that the voltammetric response is overlapped with the voltammetric limits.

\section{Conclusions}

$\mathrm{N}$-trifluoromethanesulfonyl-1-azahexa-1,3,5-triene derivatives exhibited a clear oxido-reduction mechanism when they were combined with the $\mathrm{K}_{3}\left[\mathrm{Cr}\left(\mathrm{C}_{2} \mathrm{O}_{4}\right)_{3}\right] \cdot 3 \mathrm{H}_{2} 0$ salt. In particular, the 1-trifluoromethanesulfonyl-3-[4'-(1'trifluoromethanesulfonyl)-1',4'-dihydropyridinyl]-6alylamine)-1-azahexa-1,3,5-triene was the one that more easily reacted due to the nucleophilic aperture of alylamine on the pyridone salt. This result was supported by the voltammetric response where the increase of current as the number of PSC increased, suggested a conductive film growth. Furthermore, the redox behavior of this complex suggests that the new electrodeposited material can be classified as molecular material. AFM images of the newly formed films show that the largest amount of electrodeposited material corresponds to this complex. Similar conclusion can be drawn for DS1.

Finally, in this work it was demonstrated that in situ EC-AFM allowed the visualization and morphological characterization of newly formed materials onto HOPG electrode surfaces in the presence of the electrolyte solution. This combined technique (electrochemistry and AFM) not only can help to investigate the reaction mechanism of new materials but also can help to create modified electrodes with particular morphological characteristics or textures, where the role and control of the interface could be critical to determine the final functional properties of the film.

\section{Acknowledgments}

The authors want to dedicate this work to our colleague and friend T. Hernandez-Perez. M.E. Sanchez-Vergara thanks CONACYT project number J36715-U. A. Moreno acknowledges CONACYT project number 36155.

\section{References}

1. Bryce, M. R.; J. Mater. Chem. 1995, 5, 1481.

2. Garnier, F.; Horrowitz, G.; Peng, X.; Fichou, D.; Adv. Mat. 1990, 2, 1592.

3. Plaut, D.J.; Holman, K.T.; Pivovar, A. M.; Ward, M.D.; J. Phys. Org. Chem. 2000, 13, 858.

4. Cassoux, P.; De Caro, D.; Valade, L.; Casellas, H.; Daffos B.; Vergara, M.E.S.; Mol. Cryst. Liq. Cryst. 2002, 380, 45.

5. Caro, J.; Garelik S.; Figueras, A.; Chem. Vap. Deposition 1996, 2, 251.

6. Bryce, R.F.; Devonport, W.; Goldenberg, L.M.; Wang, C.; Chem. Comm. 1998, 9, 945.

7. Figueras, A.; Garelik, S.; Caro, J.; Cifre, J.; Veciana, J.; Rovira, C.; Ribera, E.; Canadell, E.; Seffar, A.; Fontcuberta, J.; J. Cryst. Growth 1996, 166, 798.

8. de Caro, D.; Sakah, J.; Basso-Bert, M.; Faulman, C.; Legros, J.P.; Ondarcuhu, T.; Joachim, C.; Aries, L.; Valade, L.; Cassoux, P.; C. R. Acad. Sci. II C 2000, 3, 675.

9. Toscano, R.A.; Rosas R.; Hernández-Galindo, M.D.; AlvarezToledano, C.; García-Mellado, O.; Trans. Met. Chem. 1998, 23, 113 .

10. Triki, S.; Berezovsky, F.; Sala Pala, J.; Riou, A.; Molinie, P.; Synth. Met. 1999, 103, 1974.

11. Thetiot, F.; Berezovsky, F.; Triky, S.; Sala-Pala, J.; Garcia, C.J.; Hajem, A.A.; Bouguessa, S; Fabre, J.M.; C. R. Acad. Sci., Ser. II C 2003, 6, 291.

12. Moya-Cabrera, M.M.; PhD Thesis, Universidad Nacional Autónoma de México, México, 2001.

13. Hernández-Pérez, T.; Morales, M.; Batina N.; Salmón M.; J. Electrochem. Soc. 2001, 148, C369.

14. Rivera, M.; Holguín, S.; Moreno, A.; Sepúlveda-Sánchez, J.D.; Hernández-Pérez, T.; J. Electrochem. Soc. 2002, 149, E84.

15. Toccoli, T.; Boschetti, A.; Iannotta, S.; Synth. Met. 2001, 122, 229.

16. Lund, H.; Baizer, M.M.; Organic Electrochemistry: An Introduction and A Guide, $3^{\text {rd }}$ ed., Dekker: New York, 1991.

17. Toscano, R.A.; Hernández-Galindo, M.D.; Rosas, R.; GarciaMellado, O.; Portilla, F.D.; Amabile-Cuevas, C.; AlvarezToledano, C.; Chem. Pharm. Bull. 1997, 45, 957.

18. Saito, G.; Ferraris, J.P.; Bull. Chem. Soc. Jpn. 1980, 53, 2141. 